\title{
Hermeneutics of concepts of the existential-psychological healing model
}

\author{
S.I. Filippchenkova ${ }^{1, *}$, E.A.Evstifeeva ${ }^{2}$, L.A. Murashova $^{3}$ \\ ${ }^{1}$ Doctor of Psychological sciences, Tver State Medical University, 4 Sovetskaya street, 170100, Tver, Russia. \\ ${ }^{2}$ Doctor of Philosophy, Tver State Medical University, 4 Sovetskaya street, 170100, Tver, Russia. \\ ${ }^{3}$ Candidate of Psychological sciences, Tver State Medical University, 4 Sovetskaya street, 170100, Tver, Russia.
}

\begin{abstract}
The article describes an interdisciplinary research project on the management of health-related quality of life of cancer patients. The project involves theoretical and applied studies of health-related quality of life of breast cancer patients, their existential and psychological characteristics. A comparative analysis of the diagnosis of quality of life in medical (objective) and psychological (subjective) assessments was carried out. The key concepts of the existential-psychological model of healing - pain, the existential meaning of pain, illness, fear - were revealed. The possibility and effectiveness of complementation of the medical and existential-psychological models of healing using key concepts - the existential-psychological model of managing health related quality of life, existential meanings of pain, illness, fear - were analyzed. The existential-psychological model of healing is psychometric tools used for describing, explaining and generalizing psychological and existential data on a cancer patient. New psycho-diagnostic tools are used in medical professional practice taking into account requirements of personalized medicine and problems of maintaining health-related quality of life of cancer patients; adjustment of the behavior of cancer patients using existential experiences, reflexivity, trust, responsibility, and health-related quality of life.
\end{abstract}

\section{Introduction}

The Russian healthcare system is interested in personalized medicine which provides for an individual trajectory of maintaining health-related quality of life of ill people. The existential-psychological model of healing takes into account the multidimensional idea of health, proportionality of objective and subjective aspects of human well-being, their constant dynamics. In terms of medical and psychological indicators of health-related quality of life, one can distinguish between the level of claims and expectations, the degree of satisfaction with ontological medical and socio-psychological factors of life of a cancer patient.

\section{Problem Statement}

The key concepts that reveal ontological, epistemological, axiological, existential aspects of oncology as a disease are pain, the existential meaning of pain, illness, and fear.

\section{Research Questions}

The existential-psychological model of healing is a set of psychometric tools used for describing, explaining and generalizing psychological and existential data on a cancer patient. The model focuses on personal parameters of health-related quality of life of a cancer patient, his existential mood, cognitive and reflective personality characteristics. The model is "tailored" to the idea of diagnosing quality of life in terms of a subjective (existential-psychological, reflective) assessment of health. (Grishina, 2016). The oncological disease is a violation of the mechanism of controllability of our behavior manifested in changes in the existential mood, boundaries of reflexivity, responsibility, and confidence. The concept "pain" is the opposite to "health". Health is measured by its navigational value, which allows us to identify psychological and personal efforts and the will of a patient to recover. Health implies the lack of pain and correlates with a positive image. This image appears against the backdrop of the opposition of pain as a clearly negative image, since pain is an enemy of health. The phenomenon of pain accompanies every person. It is an instant that transforms into infinity - a chronic disease. Pain (Greek algesis, lat. Dolor) is an integral part of everyday and existential experience. Its manifestations are internal pressure which causes tension. The ontological context of pain is described by $\mathrm{Yu}$. Vetlesen: "Pain - whether it is physical, mental or hybrid - is immanent to a human being, and everyone lives - endures it ... It comes from the inevitable vulnerability that has always been part of human nature, but which we (and this is the cultural and historical difference of the current era from the past one) do not know how to tolerate" (Vetlesen, 2010). According to G. Hegel, pain is the essence of all living things, an objective givenness, identical to itself 
and containing an absolute contradiction, where the contradiction is real existence (Hegel, 1972). Pain is a reality, it is real, therefore it is legitimate to judge beingin-pain.

Evidence and certainty is that pain is internal pressure causing tension. Any tension requires discharging, output, stress relief. Self-destruction and self-destructive behavior are possible. In modern medical discourse, pain is defined as a sensitive or emotional unpleasant sensation, as an act of damage to tissues, organs, etc. It is affective as an incentive force and is initiated by relevant feelings when exposed to factors that are excessive. Pain is a phenomenon of subjective reality, the mental and psychological state of a person, his pathological experience. It is experimentally tested, individually and personally " objectified ".

The ontology of pain produces existential severity of pain. The existential meaning of pain is individualization of a person. The pain testifies to the existential realities of one's own existence. It lures into a situation of loneliness. It initiates a contact with itself and "calls" about selfexistence in the guises of the bodily constitution, in the projection of active and / or reactive formation, selfpreserving behavior and the psychosomatic "system".

The social reality of pain is represented by addictions, social anomie, mortality, existential loneliness, financial failure to overcome it. Today, when millions of people suffer from chronic pain which causes a socio-economic damage, social ontology of pain tells us about modern coercion technologies that "play" on the phenomenon of pain. The technologically increasing slave dependence on the pain effect suppresses the degree of freedom of a person when it "objectifies" him by giving him a drug to suppress pain. For a person, this dependence is "indecent", burdensome like any invasion into his personal space, violence against the inner world. The pain is "privatized" and must remain personal.

In modern socio-psychological pain discourse, humanitarian methods and socio-psychological practices of pain "anesthesia" are revealed. Pain is of sociocultural significance for neuroticism and psychiatry (the term suggested by M. Foucault); it teaches us to be alert for relapse of pain, to be intolerant to pain. The degree of pain, "painful" behavior checks our social adaptability, an ability and a desire for constructive or destructive coexistence.

A pain decoder is a disease that mythologizes, metaphorizes, becomes a figure of speech (Izutkin, Smirnova, 2017). Even today cancer remains a disease with an unclear etiology and multiple interpretation. Let us remember metaphors traditionally related to cancer (Sontang, 2016): identification of cancer with death, a curse, corruption, personal pejorativeness. Biophysicalist connotations of cancer are corrodes, decomposes, absorbs, devours. Psychological ones are crushed by fear and agony, emotional self-denial, long suppressed feelings, restrained rage, emotional depression, emotional trauma, manic focus on "I", reproduction of cells, etc. Moral metaphors are heavenly punishment, monstrous punishment for life, demonic guidance, treason to oneself, lack of sensitivity, etc. Personal and social predictors of cancer are personality failure, without a "nuclear" self or personality, fatality, social evil, violence and hostility. Mythological and metaphorical traps that spoil the psyche of cancer patients entail negative and even tragic consequences, such as trauma and stigmatization of consciousness, loss of control over the situation and hopes for the future, loneliness, irrational fear, despair, dependencies, vulnerability of a physical condition, etc. Only positive interpretation of the disease allows a patient to activate resources to cope with the disease, reveal the dormant psychological potential, overcome existential uncertainty.

It is known that objects of the deepest fears are identified with a disease. Oncological disease is accompanied by fears of death, ugliness, powerlessness, sacrifice, powerlessness, decay, evil. The horror of cancer effects is disfigurement, amputation of body parts. Unlike other diseases (tuberculosis, cardiovascular pathology), cancer is a disease of abnormal proliferation of the whole organism.

Perception of pain and disease is correlated with fear. Fear is an ontological feeling, an essential expression of "I" in reactions and attitudes to the external world. Fear is a phenomenon of the unconscious, conscious, reflective, and personal levels that permeates value-semantic and active-volitional structures of psychic reality. Fear in its various forms (neurotic, paranoid, social, etc.) and degrees (anxiety, fear, horror, phobias, etc.) is physically constituted, situationally determined by a certain disease. The dynamics, scale, and modifications of fear indicate its permanent mutability caused by life activity under the total risk and uncertainty. The meaning of fear has evolved to the phenomenon of culture, when fear becomes the basis for self-esteem and self-control, as well as control over the behavior of other people. The cultivation of fear and its functionality expanded to rationalization. This allowed fear to become a flexible attitude.

A retrospective analysis shows that identification and phenomenology of fear correlate with a low-level negative content. In a state of fear, a person ceases to distinguish his capabilities, the potential for resistance to something. Axiologically, this is seen and designated as an unseemly act, dishonor, cowardice and even shame.

Fear is an existential, a priori structure, a feeling that generates meaning-life forces. M. Heidegger speaks of fear as an opportunity: "All modifications of fear indicate the possibility of disposition that a being as a being-inthe-world is "subject to fear". This "susceptibility to fear" should not be understood in the ontical sense of an actual, "isolated" disposition, but as an existential possibility of an essential disposition" (Heidegger, 2003). Fear can have its positive meanings. In case of cancer, it can help bet on will, reflection, responsibility. Person's behavior, his well-being, life sentiment, and quality of life largely depend on the regulation of the "measure" of fear.

\section{Purpose of the Study}

The study "Managing quality of life related to health in oncology: interdisciplinary approaches, an existentialpsychological model of healing" was conducted. The 
main purpose is to develop and test an existentialpsychological model for managing quality of life based on a personalized approach to the treatment of breast cancer patients.

To achieve the goal, interrelated tasks were solved: to identify communicative features of the subjects of treatment (doctors, patients), to develop an existentialpsychological model of managing health-related quality of life of cancer patients; to explicate existentialpsychological characteristics, reflective positioning of cancer patients (breast cancer) as indicators of subjective well-being; on the basis of a comparative analysis of objective (medical) and subjective (psychological) indicators of quality of life, to identify individual psychological factors affecting the "integral picture" of the subjective well-being of a cancer patient; to develop an existential-psychological model of healing in oncological practice and reveal its managerial potential for a comprehensive diagnosis of health-related quality of life; to test comprehensive medical and psycho-diagnostic tools for assessing health-related quality of life of breast cancer patients used in professional and research activities of oncologists and introduce project results into medical practice to expand medical, psychological, diagnostic and therapeutic tools for assessing health-related quality of life of a cancer patient.

\section{Research Methods}

The methodological basis of the project is post-nonclassical scientific rationality (Lepsky, 2013), an interdisciplinary approach, the concept of personalized medicine (Sadkovsky, 2014). Health-related quality of life is a complex concept revealed in its interdisciplinary content as an objective and subjective expression of the existential state of a person, his medical (physical) and psychological health (Novik, 2000).

\section{Findings}

The project is aimed to study quality of life related to the health of cancer patients (breast cancer), their existential and psychological characteristics. A comparative analysis of health-related quality of life was carried out. A comprehensive medical and psychological interdisciplinary study began in 2018 and will be completed in 2020. 200-250 breast cancer patients and 3040 medical workers of Tver Regional Clinical Oncology Hospital participated in the study. The base of the empirical research is a psycho-diagnostic laboratory of Tver State Medical University. The psychodiagnostic research tools are as follows: the SF-36 method (healthrelated quality of life) (Instructions for processing data obtained using the SF -36 questionnaire, 2019), SHE test developed by A. Langle and K. Ogler (study of existential attitudes affecting the assessment of quality of life during the disease using the existence scale (Krivtsova et al., 2009), the diagnostics method for the level of reflexivity by A.V. Karpov (to measure the reflexive potential) (Karpov, 2003), the questionnaire of the level of subjective control by J. Rotter (USK) (to measure responsibility); the questionnaire of a self-confidence level (to study trust in interpersonal relationships) (Skripkina, 2006; Skripkina et al., 2013), the diagnostic technique for communicative and organizational inclinations (KOS-2) by N.P. Fetiskina (analysis of the communicative potential of physicians and patients) (Fetiskin et al., 2002). These psychological data will be processed using a computer program SPSS which will create an extensive database. Based on the results of the empirical study, an existential-psychological model for managing health-related quality of life of cancer patients has been developed taking into account the communication potential of doctors treating cancer (Lepsky et al., 2010). A specialized technique for the comprehensive medical and psychological diagnosis of health-related quality of life of cancer patients is being developed.

\section{Conclusion}

The article discusses feasibility and effectiveness of complementing medical and existential-psychological healing models with the help of key concepts - the existential-psychological model of managing life quality associated with health of cancer patients, existential meanings of pain, illness, fear. New psycho-diagnostic tools can be used in medical professional practice taking into account requirements of personalized medicine and quality of life of cancer patients; adjustment of the behavior of cancer patients using existential experiences, reflexivity, trust, responsibility, and health-related quality of life.

The study was financially supported by the Russian Fund of Fundamental Research Federal as part of scientific project No. 19-013-00038 "Management of quality of life related to health of cancer patients: interdisciplinary approaches, the existentialpsychological healing model”.

\section{References}

1. I.A. Sadkovsky, IJCM, PPPM (Predictive, Preventive and Personalized Medicine) as a new model of national and international healthcare service and thus a promising strategy to prevent a disease: from basics to practice, 5, 855-870.

2. A.Yu. Vetlesen, Philosophy of pain. (Progress Tradition, 2010)

3. G.V.F. Hegel, The Science of Logic. In 3 vols.. 3, (Mysl, 1972)

4. D.A. Izutkin, N.E. Smirnova, Playing with the disease. Man, 1, 174-182. (2017).

5. Instructions for processing data obtained using the survey list. Retrieved from: http://therapy.irkutsk.ru/doc/sf36a.pdf. (2019).

6. A.V Karpov, Psychological journal, Reflexivity as a mental property and methods for its diagnosis. 24, 5, 45-57 (2003).

7. S.V. Krivtsov, A. Langley, K. Orgler, Existential analysis scale existence (Existenzskala) A. Langley and K. Orgler, Bulletin 1, 141-170. (2009). 
8. Lepsky, V.E. Collection of materials of the International Symposium. Ethical Aspects in V.A. Models Lefebvre in the context of the evolution of ideas about scientific rationality. Reflective processes and management. 43-56 (Moscow: Kogito-Center, 2013)

9. A.A Novik, S.A Matveev, T.I Ionova. Clinical medicine, Assessment of the quality of life of a patient in medicine, 2, 10-13. (2000)

10. V.I. Arshinov, V.E. Lepsky, The problem of assembly of subjects in the post-nonclassical science. Retrieved from: http://www.reflexion.ru/Library/Lepsky2010sborka.pdf (2010)
11. S. Sontang, Illness as metaf ora. (Ad Margin Press, 2016)

12. T.P. Skripkina, Trust in socio-psychological interaction (RP GU, 2006)

13. T.P. Skripkina, T.N.Sherbakova, Trust as a condition for the development of communicative competence of subjects of educational activity: a training manual. Retrieved from: http : // userdocs . com / psihologiya / 84798 / index . html ? page $=7$. (2013).

14. N.P. Fetiskin, V.V. Kozlov, G.M. Manuilov, Sociopsychological diagnosis of personality development and small groups. Retrieved from: http:/www.gurutestov.ru/test/247/ (2002)

15. M. Heidegger, Being and Time (Folio, 2003 